\title{
Reference loci for RT-qPCR analysis of differentiating human embryonic stem cells
}

\author{
Liesbeth Vossaert ${ }^{1}$, Thomas O'Leary ${ }^{2}$, Christophe Van Neste ${ }^{1}$, Björn Heindryckx ${ }^{2}$, Jo Vandesompele ${ }^{3}$, \\ Petra De Sutter ${ }^{2}$ and Dieter Deforce ${ }^{1 *}$
}

\begin{abstract}
Background: Selecting stably expressed reference genes is essential for proper reverse transcription quantitative polymerase chain reaction gene expression analysis. However, this choice is not always straightforward. In the case of differentiating human embryonic stem (hES) cells, differentiation itself introduces changes whereby reference gene stability may be influenced.

Results: In this study, we evaluated the stability of various references during retinoic acid-induced ( 2 microM) differentiation of hES cells. Out of 12 candidate references, beta-2-microglobulin, ribosomal protein L13A and Alu repeats are found to be the most stable for this experimental set-up.

Conclusions: Our results show that some of the commonly used reference genes are actually not amongst the most stable loci during hES cell differentiation promoted by retinoic acid. Moreover, a novel normalization strategy based on expressed Alu repeats is validated for use in hES cell experiments.
\end{abstract}

Keywords: Reverse transcription quantitative PCR, Normalization, Reference genes, Alu repeats, Human embryonic stem cells, Stem cell differentiation

\section{Background}

Human embryonic stem (hES) cells, derived from the inner cell mass of a blastocyst stage embryo, are able to differentiate into all cell types of the adult body and have the potential for unlimited growth [1-4]. As a consequence of their pluripotency and self-renewal capacity, hES cells are ideal for investigating the basic mechanisms of development and cell differentiation. In addition, they may be a source of differentiated cells of a particular cell type, to be used in toxicity screening, cell replacement therapies and many other applications $[3,5]$.

Pluripotent cells are characterized by several features, such as the expression of pluripotency factors (Oct4 (encoded by POU5F1), Nanog (NANOG) and Sox2 (SOX2)), the presence of specific cell surface antigens (e.g. SSEA-3, SSEA-4, TRA-1-60 and TRA-1-81), and distinct chromatin signatures [3,6-9].

To date, the molecular basic mechanisms of (spontaneous) hES cell differentiation and development are

\footnotetext{
* Correspondence: Dieter.Deforce@UGent.be

'Laboratory for Pharmaceutical Biotechnology, Ghent University, Harelbekestraat 72, Ghent 9000, Belgium

Full list of author information is available at the end of the article
}

largely unknown $[4,10]$. Differentiation can be induced in vitro under specific culture conditions, such as the addition of retinoic acid, a morphogen commonly used for multilineage differentiation of ES cells in general and for specific development along the neural lineage [11-13]. Amongst other techniques, reverse transcription quantitative polymerase chain reaction (RT-qPCR) is very well suited for monitoring pluripotency and differentiation, as it allows accurate messenger RNA quantification of numerous samples at the same time $[14,15]$. In the context of hES cell characterization, RT-qPCR is applied for evaluating the expression of the transcription factors Oct4 and Nanog, since the expression of these core pluripotency circuitry members [9] decreases significantly within a few days after onset of differentiation $[10,11]$.

For proper RT-qPCR data evaluation, several variables need to be taken into account. These include sample handling and storage, starting material quantity and quality, efficiency of different enzymatic reaction steps and overall transcriptional activity differences between cells $[14,16]$.

To correct for these variables, different normalization methods have been reported. Gene expression levels can be standardized to cell number, however, it is not always 
possible to obtain an accurate enumeration of cells. In addition, this strategy does not consider possible insufficient enzymatic reaction efficiencies [14,17]. Alternatively, data are normalized for RNA mass quantity, although this is not always representative for the mRNA content. Ribosomal RNA molecules make up the major part of the total RNA mass and may be regulated, thus resulting in a variable rRNA/mRNA ratio [14,16-18]. The most frequently utilized strategy is the inclusion of one or preferably more reference genes as an internal standard. The expression of these references should ideally not vary between cells of interest or as a consequence of experimental handling $[14,16,17,19]$.

Selecting stable reference genes is critical for correct interpretation of RT-qPCR data. However, when studying differentiating hES cells, proper reference gene selection is not straightforward. Differentiation does not only include various morphological changes, but also major alterations in gene expression levels of numerous genes. The regulation of some reference genes may be associated with these cellular changes, hence the stability of the used references has to be evaluated. The available differentiation protocols may induce distinct gene expression variability, which impedes finding stably expressed reference genes over the different samples and making protocol-dependent optimization required $[10,14,16,17,19,20]$.

In this study, we emphasize the importance of determining suitable reference genes by performing an expression stability analysis for retinoic acid induced differentiating hES cells, using the geNorm ${ }^{\text {PLUS }}$ algorithm in the qbase $^{\text {PLUS }}$ software (Biogazelle) [14,21]. The possibility of co-regulation was reduced by opting for 11 candidate reference genes from different functional categories [14]. In addition to these candidates, a new normalization strategy was applied, based on the measurement of expressed Alu repeats.

Alu insertions are repetitive DNA sequences, approximately 300 base pairs (bp) long and occurring generally at high copy number in introns, $3^{\prime}$ untranslated regions (UTR) of genes and intergenic genomic regions [22]. These short interspersed mobile elements are not equally spread throughout the human genome, since they preferentially accumulate in gene-rich regions [16,22]. In total, Alu elements comprise more than $10 \%$ of the genome mass, thus being the most abundant of all mobile elements and they are divided in several well-conserved subfamilies (e.g. AluSq, AluSx, AluY) $[16,22,23]$. Alu repeats, named after a recognition site for the restriction enzyme Alu I, are thought to be amplified by retrotransposition, a process in which the Alu element is transcribed by RNA polymerase III, followed by reverse transcription and incorporation into the genome [16,22-24].

Because of their genome-wide distribution, including in the 3' UTR of protein coding genes, individual gene expression variability in the cells of interest will not substantially influence total Alu element expression. This feature makes the Alu repeats a valuable and interesting strategy for RT-qPCR normalization for biological systems such as differentiating stem cells $[16,22]$.

\section{Results}

Human ES cells were induced to differentiate for several days by addition of retinoic acid to the culture medium. The fading undifferentiated state of hES cells was assessed morphologically, using light microscopy. Differentiation was initially visible at the colony periphery where cells start to pile-up, and in comparison to undifferentiated cells, differentiating colonies lost their round shape with welldefined borders, as illustrated in Figure 1.

To confirm differentiation, the expression levels of pluripotency genes POUSF1 and NANOG can be followed over time using RT-qPCR. For this purpose, the most stable normalization references were determined by means of a stability analysis using the geNorm ${ }^{\text {PLUS }}$ application in qbase $^{\text {PLUS }}$. The stability of 12 candidate references (see Table 1 for gene names and function) was analyzed for a first series of samples, which were isolated every 24 hours during 8 days of differentiation (= Experiment 1$)$. In the stability ranking, $\beta$-2-microglobulin (B2M), ribosomal protein L13A (RPL13A) and Alu repeats (AluSq) were found to be the most stable reference loci for this experimental set-up (reference stability ranking displayed in Table 2). The stability measure ( $\mathrm{M}$ value, see Additional file 1 ) of these three references varied from 0.277 to 0.290 , which indicates a high stability in comparison to the other candidates, as $\mathrm{M}$ values up to 0.500 are considered acceptably stable for homogenous samples [21]. In the determination of the optimal reference number, two appeared to be sufficient for RT-qPCR normalization, as the pairwise variation (V value) was approximately 0.09 for upgrading from two to three reference loci $(\mathrm{V} 2 / 3)$. V values less than 0.15 indicate that increasing the number of references would not add any more significant value to the assay.

As a confirmation for this first experiment, a reference stability analysis was performed during two more hES cell differentiation experiments. For experiment 2 samples were collected every 24 hours during 6 days, and a third series was collected every 4 hours during day 3,4 and 5 after onset of differentiation (= Experiment 3). Again, the same three reference loci were found to be the most stable in both experiments (Table 2). The $\mathrm{M}$ values for $B 2 M$, RPL13A and AluSq varied from 0.203 to 0.221 , and from 0.378 to 0.386 for Experiment 2 and 3 respectively (all $\mathrm{M}$ values can be found in Additional file 1). Also in both cases, two references were shown to be enough for normalization, considering the low $\mathrm{V} 2 / 3$ values.

Subsequently, the expression data of POU5F1 and NANOG were normalized applying two different reference 

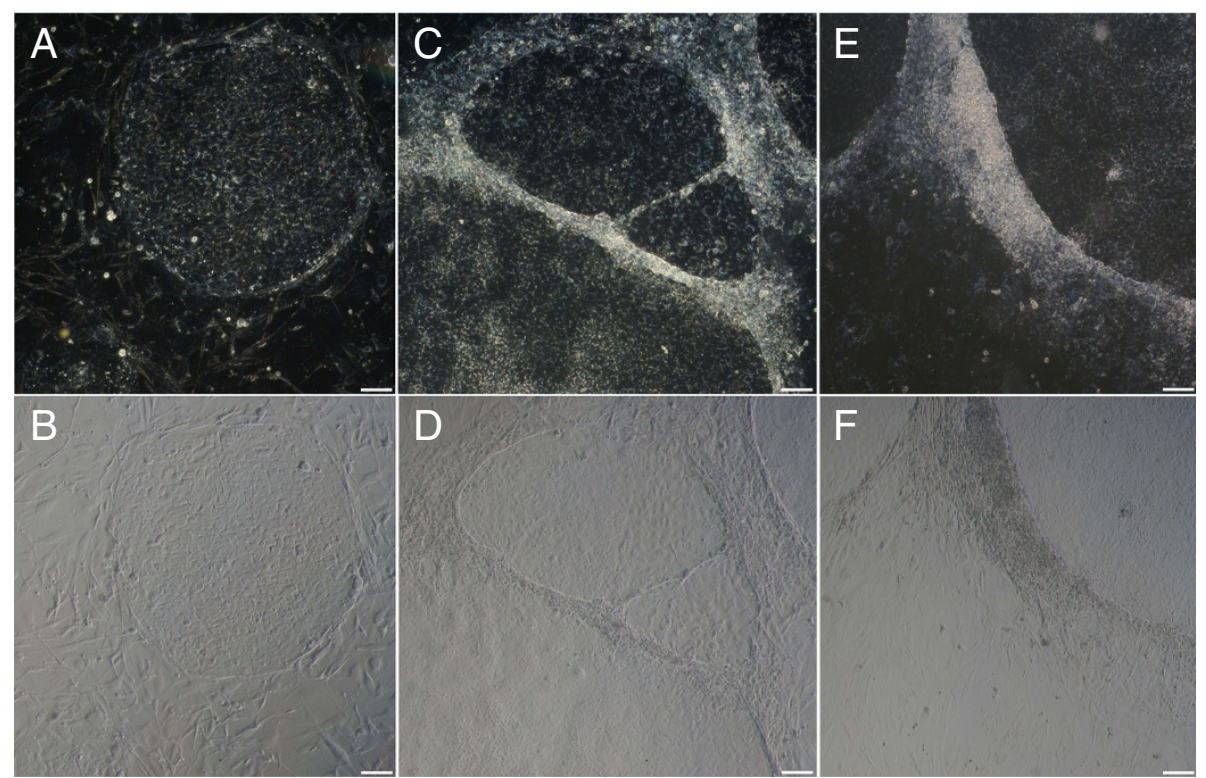

Figure 1 Morphological evaluation of human embryonic stem cell culture. Comparison of an undifferentiated colony (A: phase contrast, B: bright field image) with differentiated hES cells on day 3 (C, D) and day 5 (E, F) after retinoic acid induction (scale bars $=100 \mu \mathrm{m}$ ).

sets: relative quantification using three commonly used genes (GAPDH, ACTB and PPIA) versus the three most stable references determined in the analyses described above (B2M, RPL13A and AluSq).

As can be expected, this comparison revealed a substantial difference in the change of expression levels of
POU5F1 and NANOG, emphasizing the importance of proper reference gene selection. As illustrated for Experiment 2 in Figure 2, the decrease in expression of these pluripotency factors is significantly less pronounced using the 'traditional' reference genes (GAPDH, ACTB and PPIA) than with the most stable reference loci as

Table 1 Reference loci and target genes included in the experiments

\begin{tabular}{|c|c|c|c|c|c|}
\hline Reference & Name & NCBI RefSeq & Function & $\begin{array}{l}\text { Amplicon } \\
\text { size (bp) }\end{array}$ & $\begin{array}{l}\text { Exon } \\
\text { location }\end{array}$ \\
\hline$\overline{\mathrm{ACTB}^{*}}$ & Beta-Actin & NM_001101 & Cytoskeletal protein & 173 & $7 \mathrm{p} 22$ \\
\hline$\overline{\mathrm{B} 2 \mathrm{M}^{\S}}$ & Beta-2-microglobulin & NM_004048 & Major histocompatibility complex I component & 86 & $15 q 21-q 22$ \\
\hline $\mathrm{GAPDH}^{*}$ & $\begin{array}{l}\text { Glyceraldehyde-3-phosphate } \\
\text { dehydrogenase }\end{array}$ & NM_002046 & Oxidoreductase in glycolysis and gluconeogenesis & 111 & $12 \mathrm{p} 13$ \\
\hline $\mathrm{HMBS}^{*}$ & Hydroxymethyl-bilane synthase & NM_000190 & Porphyrin metabolism and heme synthesis & 64 & $11 q 23$ \\
\hline $\mathrm{HPRT}^{*}$ & Hypoxanthine phosphoribosyl-transferase 1 & NM_000194 & Purine synthesis in salvage pathway & 94 & $x q 26$ \\
\hline $\mathrm{PPIA}^{*}$ & Peptidylprolyl isomerase A (Cyclophilin A) & NM_021130 & $\begin{array}{l}\text { Catalyzation of cis-trans isomerization of proline } \\
\text { imidic peptide bonds }\end{array}$ & 71 & $7 \mathrm{p} 13$ \\
\hline$\overline{\text { RPL13A }}{ }^{*}$ & Ribosomal protein L13A & NM_012423 & 605 ribosomal subunit structural component & 126 & $19 q 13$ \\
\hline $\mathrm{SDHA}^{*}$ & $\begin{array}{c}\text { Succinate dehydrogenase complex, } \\
\text { subunit A }\end{array}$ & NM_004168 & $\begin{array}{c}\text { Electron transporter in citric acid cycle and } \\
\text { respiratory chain }\end{array}$ & 86 & $5 p 15$ \\
\hline$\overline{\mathrm{TBP}^{*}}$ & TATA box binding protein & NM_003194 & General transcription factor for RNA polymerase II & 89 & $6 q 27$ \\
\hline$\overline{\mathrm{UBC} C^{*}}$ & Ubiquitin C & NM_021009 & Involved in protein degradation & 133 & $12 q 24$ \\
\hline YWHAZ & $\begin{array}{c}\text { Tyrosine 3-monooxygenase / tryptophan } \\
\text { 5-monooxygenase activation protein, zeta } \\
\text { polypeptide }\end{array}$ & NM_003406 & $\begin{array}{l}\text { Signal transduction; binds to phosphorylated serine } \\
\text { residues on several signaling molecules }\end{array}$ & 94 & $2 p 25$ \\
\hline AluSq & Alu repeats, subfamily $\mathrm{Sq}$ & & & & \\
\hline POU5F1 $1^{\S}$ & POU class 5 homeobox 1 , Oct4 & NM_002701.4 & Marker for embryonic stem cell pluripotency & 130 & $6 \mathrm{p} 21$ \\
\hline NANOG $^{*}$ & Nanog homeobox & NM_024865.2 & Marker for embryonic stem cell pluripotency & 109 & $12 \mathrm{p} 13$ \\
\hline
\end{tabular}

"exon-spanning primer pair; ${ }^{{ }^{\circ}}$ forward and reverse primer localized in the same exon. 
Table 2 Reference stability analysis

\begin{tabular}{llll}
\hline & Experiment $\mathbf{1}$ & Experiment 2 & Experiment 3 \\
\hline 1 & B2M & B2M & B2M \\
2 & AluSq & AluSq & RPL13A \\
3 & RPL13A & RPL13A & AluSq \\
4 & HPRT1 & GAPDH & PPIA \\
5 & YWHAZ & SDHA & GAPDH \\
6 & TBP & TBP & HPRT1 \\
7 & HMBS & YWHAZ & TBP \\
8 & ACTB & ACTB & YWHAZ \\
9 & GAPDH & HPRT1 & HMBS \\
10 & PPIA & PPIA & SDHA \\
11 & SDHA & HMBS & ACTB \\
12 & UBC & UBC & UBC \\
\hline
\end{tabular}

Reference stability was analyzed for three independent $\mathrm{hES}$ cell differentiation experiments, applying the geNorm ${ }^{\text {PLUS }}$ algorithm. Results are displayed with decreasing stability from top to bottom (specific $M$ values can be found in Additional file 1).

defined in this study (B2M, RPL13A and AluSq) (ANOVA, $\mathrm{p}$-value $=1.30 \mathrm{e}-05)$. Also for the other two experiments a significant difference was seen ( $p$-value $=0.0034$ and $=0.0215$ for Experiment 1 and 3 respectively).

\section{Discussion}

Human ES cells provide a unique opportunity to study early development and may hold great potential for regenerative medicine $[3,5,8,11]$. The transcription factors Oct4 (POU5F1) and Nanog (NANOG) contribute to selfrenewal and are required for maintaining the pluripotent state of hES cells $[6,9]$. Therefore, the expression of these factors is commonly assessed with RT-qPCR, as mRNA levels decrease significantly within a few days after inducing differentiation $[10,11]$. Morphological evaluation of the differentiating cells shows that hES cells start to accumulate at the edges of the colonies and that individual cells adopt a more lengthened, neuronal-like phenotype during early hES cell differentiation (Figure 1) [25].

Adequate RT-qPCR normalization is essential for valid data interpretation. However, in vitro hES cell differentiation entails massive gene expression alterations in general and specifically due to the differentiation agent itself, whereby the expression of individual reference genes may vary, thus making it difficult to select the most suitable and stable references $[10,15]$. Synnergren and colleagues (2007) already made note of a unique reference gene expression pattern when differentiating hES cells spontaneously [20]. And as Willems et al. (2006) also showed, normalization results vary significantly depending on the reference used [19].

In this study, the suitability of 12 different references was evaluated using the geNorm ${ }^{\text {PLUS }}$ algorithm [14,21]. From our results, it can be concluded that B2M, RPL13A

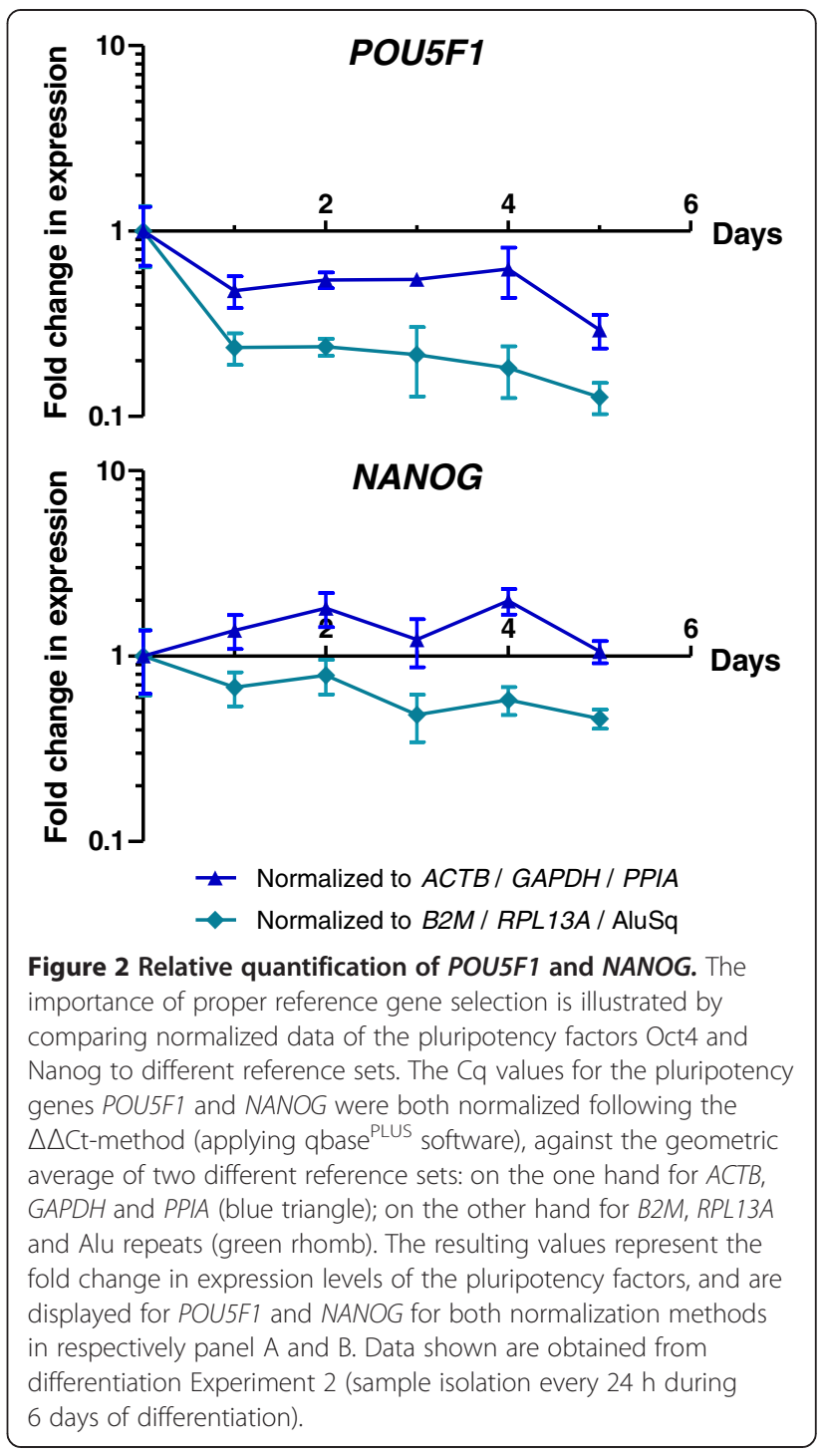

and Alu repeats (AluSq) are the most stable reference loci for this specific differentiation protocol. The use of two references was shown to be sufficient for accurate normalization of RT-qPCR data, though generally the use of three stable references is recommended in literature [14].

The importance of selecting the most stable and suitable references is illustrated by normalization of gene expression levels of pluripotency factors Oct4 and Nanog. Comparison of B2M, RPL13A and AluSq with more 'traditional' reference genes, resulted in a significantly different normalization, indicating that classic reference genes such as GAPDH are not always appropriate for a given set-up. In the field of stem cell differentiation, optimization is required for each specific differentiation protocol.

Despite the comparability of different algorithms for determining reference stability (Normfinder, Bestkeeper, Comparative Delta-Ct method), their application may 
result in a slightly different stability order in comparison with the geNorm ${ }^{\text {PLUS }}$ applet. This may indicate though that different reference sets are applicable, resulting in analogous normalization data. When applying those algorithms to the results of Experiment 1, Alu repeats and RPL13A remain among the Top 3 stable reference loci (data not shown). B2M deteriorates a few ranks when using Normfinder and Bestkeeper, and is replaced by $T B P$ as a more stable reference. Nevertheless, the comparison of normalization data for B2M, RPL13A \& AluSq and TBP, RPL13A \& AluSq, gave no significant difference (p-value $>0.5$ ). In conclusion, B2M, RPL13A and AluSq are suitable reference loci for this experimental set-up of retinoic acid induced hES cell differentiation.

$\beta$-2-microglobulin (B2M) is a component of major histocompatibility complex I, hence being expressed in every nucleated cell, and has yet been applied before as a normalization scalar in different set-ups [26-28]. Ribosomal protein L13A (RPL13A) is involved in the process of transcript translation, and has also been widely included as a reference gene for RT-qPCR analyses [29-32], in spite of possible presence of pseudogenes [33]. However, pseudogene detection does not necessarily imply that a specific reference is not usable. The main point of interest is the reference stability, which in this case is clearly maintained as supported by the data described above. In our hands both $B 2 M$ and RPL13A repeatedly do come forward as a stable reference, supporting their use as normalization genes.

The fact that Alu repeats were one of the best scoring reference loci in the described analyses is not surprising. Because of their genome-wide distribution, they can be considered as a measure for the total amount of mRNA, and the overall Alu element expression will not be influenced by a variation in expression of individual genes $[16,22,34]$. For this reference, primer specificity is of minor importance. The more sequences are detected by the assay, the less the impact of individual expression variations on the total Alu content. Hence, Alu repeats provide a new strategy for reliable normalization of RTqPCR data, in particular in experiments where dramatic changes are expected. An additional advantage when working with limited amounts of starting material, is that the input can be lowered, since Alu repeats are highly expressed and thus lead to low Cq values [16].

\section{Conclusions}

This study shows that some of the commonly used reference genes cannot always be included as a stable normalization scalar. Selection of suitable references is highly dependent on the experimental set-up, as is illustrated here for early hES cell differentiation induced by retinoic acid. Furthermore, a new normalization strategy based on Alu repeat expression is proposed and validated for hES cell (retinoic acid induced) differentiation experiments.

\section{Methods}

\section{Human embryonic stem cell cultures and sample preparation}

Human ES cells (UGENT 1 and UGENT2 cell line) were generated in-house [35]. The cells were cultured in 6-well dishes or flasks on a nearly confluent layer of Mitomycin C (Sigma-Aldrich, Steinheim, Germany, \#M4287) treated mouse embryonic fibroblasts (MEF, passage 3), in Knockout DMEM (\#41965-039) supplemented with KO-serum replacement (\#10828-010), antibiotics (PenStrep, \#15140122), L-glutamine (\#25030-024), basic fibroblast growth factor (bFGF, \#13256-059), non-essential amino acids (\#11140-035, all culture medium products purchased from Invitrogen, Carlsbad, CA, USA) and beta-mercaptoethanol (Sigma-Aldrich, \#M7522) and incubated at $37^{\circ} \mathrm{C}, 5 \% \mathrm{CO}_{2}$.

Differentiation of hES cells was induced by adding $2 \mu \mathrm{M}$ retinoic acid (Certa, Braine-l'Alleud, Belgium, \#640327 T) to the culture medium, and eliminating bFGF. Cells were harvested using 0.25\% trypsin-EDTA (Invitrogen, \#15596026) and glass beads (Sigma-Aldrich, \#Z265926-1EA). For Experiment $1 \mathrm{hES}$ cells (passage 30 ) were isolated every 24 hours during 8 days after onset of differentiation, plus an extra sample on day 12. In Experiment 2 (passage 43), samples were also collected every 24 hours, during 6 days. For Experiment 3 (passage 32), samples were collected every 4 hours during day 3,4 and 5 after differentiation was induced. For each time point, approximately $2 \times 10^{5}$ cells were isolated.

The hES cells were split two days before the start of a differentiation experiment, using 1\% collagenase (Type IV, Invitrogen, \#17104-019) and glass beads.

\section{Microscopy}

Phase contrast and bright field images of the hES cell culture were acquired with an Axiovert 25 light microscope (Carl Zeiss, Munich, Germany) (objective magnification $5 \times$ ) and a Sony Alpha 100 camera.

\section{RNA isolation and RNA quality assessment}

After isolation, the cells were immediately resuspended in $1 \mathrm{~mL}$ of TRIzol (Invitrogen, \#15596-026) and stored at $-80^{\circ} \mathrm{C}$. For RNA isolation, $200 \mu \mathrm{L}$ chloroform (SigmaAldrich, \#C2432) was added to the thawed samples, with subsequent phase separation and purification using an RNeasy Mini kit (Qiagen, Valencia, CA, USA, \#74104). After DNase treatment (Qiagen, \#79254) and a washing step, RNA was eluted and concentrated using Vivacon 500 spin columns (Sartorius Stedim Biotech, Aubagne Cedex, France, \#VN01H32).

RNA quality was assessed for a representative set of samples (6 extra samples taken during Experiment 1) by 
means of microfluidic capillary electrophoresis. An RNA HighSens Chip (Experion, Bio-Rad Laboratories, Hercules, CA, USA, \#7007105) was used to determine a $18 \mathrm{~S} / 28 \mathrm{~S}$ rRNA ratio and an RNA quality index (RQI), after determining RNA concentrations using a Quant-iT RiboGreen RNA kit (Invitrogen, \#R11490). The 18S/28S rRNA ratio's ranged from 1.59 to 1.78 and the RQI's from 8.7 to 9.9, which indicate good quality samples.

\section{cDNA synthesis}

Complementary DNA (cDNA) was synthesized using a Superscript II kit with oligo(dT) primers (Invitrogen, \#11904-018). The cDNA concentration was determined with a Quan-iT OliGreen ssDNA Assay kit (Invitrogen, \#O11492), using a spectrophotometer (Tecan, Männedorf, Switzerland). Samples were stored afterwards at $-20^{\circ} \mathrm{C}$.

\section{Reverse transcription quantitative PCR}

Two different devices were used for RT-qPCR. When using the LightCycler 480 (Roche, Basel, Switzerland), for each reaction $2 \mu \mathrm{l}$ of cDNA $(2.5 \mathrm{ng} / \mu \mathrm{l})$ was mixed with $3 \mu \mathrm{l}$ of mastermix, in a 384-well plate. Utilising the ABI Prism 7000 Sequence Detection System (Applied Biosystems, Foster City, CA, USA), each reaction consisted $5 \mu \mathrm{l}$ of cDNA $(2 \mathrm{ng} / \mu \mathrm{l})$ and $20 \mu \mathrm{l}$ of mastermix, in a 96well plate. The same thermocycling conditions were applied for both systems: $2 \mathrm{~min}$ at $95^{\circ} \mathrm{C}$ before 45 cycles of $15 \mathrm{sec}$ at $95^{\circ} \mathrm{C}$ followed by $1 \mathrm{~min}$ at $60^{\circ} \mathrm{C}$. When applicable, an additional heating step from $60^{\circ} \mathrm{C}$ to $95^{\circ} \mathrm{C}$ was added to obtain melting curves.

The mastermix comprises the primers, iTaq Supermix with ROX (Bio-Rad Laboratories, \#1725855) and water. Depending on the locus of interest, probes were included or iTaq Supermix containing SYBR Green (\#1725851) was used.

The primers for $A C T B$ (Forward: AGAAAATCTGG CACCACACC; Reverse: TAGCACAGCCTGGATAGC AA, SYBR Green detection), and primers and 6-FAMprobes for PPIA (F: CAAATGCTGGACCCAATACAAA; R: GCCATCCAACCCCTCAGTCT; Probe: TGTTCCC AGTGTTTCATCTGCACTGCC) and GAPDH (F: AGC CTCAAGATCAGCAATG; R: ATGGACTGTGGTCAT GAGTCCTT; Probe: CCAACTGCTTAGCACCCCTG GCC) were designed and validated in-house (obtained from Applied Biosystems). These primers were applied at a concentration of $300 \mathrm{nM}$. The primer sequences for the remaining references (final concentration $250 \mathrm{nM}$, all detected with SYBR Green) are available in the RTPrimerDB database (http://www.rtprimerdb.org) [36]: B2M (RTPrimerDB ID \#2), HMBS (\#4), HPRT1 (\#5), RPL13A (\#6), SDHA (\#7), UBC (\#8), YWHAZ (\#9). The primer sequences for TBP are described in [32]. The sequence of the Alu repeats primers is CATGGTGAAA CCCCGTCTCTA for the forward primer and GCCTCA
GCCTCCCGAGTAG for the reverse primer. TaqMan assays (Applied Biosystems) were used for the analysis of POU5F1 (Hs01895061_u1) and NANOG (Hs02387400_g1). All reactions were performed in duplo and no template controls were included for all genes. All primer efficiencies lie within the range of $90 \%$ to $110 \%$.

\section{Data analysis}

Stability analysis of the different references was performed using the geNorm ${ }^{\text {PLUS }}$ application in the qbase ${ }^{\text {PLUS }}$ software version 2.0 (Biogazelle) [14,21]. Relative quantification of the pluripotency markers data (Oct4 and Nanog) was calculated using the qbase ${ }^{\text {PLUS }}$ software version 2.0. Each sample is relative to a calibrator, in this case undifferentiated human embryonic stem cells (day 0), and is normalized for three reference loci; for GAPDH, ACTB and PPIA on the one hand, or B2M, AluSq and RPL13A on the other hand.

The relative quantification data for both normalization strategies were statistically analyzed performing an analysis of variance (ANOVA) in R (version 2.13.1).

\section{Additional file}

Additional file 1: Reference stability analysis: $M$ values. Reference stability ranking with specific $M$ values, as determined by the geNorm ${ }^{\text {PLUS }}$ algorithm, for Experiment 1, 2 and 3.

\section{Competing interests}

The authors declare that they have no competing interests.

\section{Authors' contributions}

LV conducted the experiments and drafted the manuscript. TO, BH and PDS provided the human embryonic stem cell cultures and commented on the manuscript. CVN performed the statistical analyses. JV participated in the experimental design and commented on the manuscript. DD participated in the experimental design and gave assistance in drafting the manuscript. All authors read and approved the final manuscript.

\section{Acknowledgements}

The authors thank N. Yigit for the technical assistance during the conduction of the RT-qPCR. This research was partially supported by a grant of the Flemish Foundation for Scientific Research (FWO-Vlaanderen, grant FWO-3G062910). PDS is holder of a fundamental clinical research mandate by FWO-Vlaanderen.

\section{Author details}

${ }^{1}$ Laboratory for Pharmaceutical Biotechnology, Ghent University, Harelbekestraat 72, Ghent 9000, Belgium. ${ }^{2}$ Department for Reproductive Medicine, Ghent University Hospital, De Pintelaan 185, Ghent 9000, Belgium. ${ }^{3}$ Center for Medical Genetics, Ghent University Hospital, De Pintelaan 185, Ghent 9000, Belgium.

Received: 30 May 2012 Accepted: 11 September 2013 Published: 12 September 2013

\section{References}

1. Thomson JA, Itskovitz-Eldor J, Shapiro SS, Waknitz MA, Swiergiel JJ, Marshall VS, Jones JM: Embryonic stem cell lines derived from human blastocysts. Science 1998, 282:1145-1147.

2. Amit $M$, Carpenter MK, Inokuma MS, Chiu CP, Harris CP, Waknitz MA Itskovitz-Eldor J, Thomson JA: Clonally derived human embryonic stem cell lines maintain pluripotency and proliferative potential for prolonged periods of culture. Dev Biol 2000, 227:271-278. 
3. Smith KP, Luong MX, Stein GS: Pluripotency: toward a gold standard for human ES and iPS cells. J Cell Physiol 2009, 220:21-29.

4. Bhattacharya B, Miura T, Brandenberger R, Mejido J, Luo Y, Yang AX, Joshi BH, Ginis I, Thies RS, Amit M, Lyons I, Condie BG, Itskovitz-Eldor J, Rao MS, Puri RK: Gene expression in human embryonic stem cell lines: unique molecular signature. Blood 2004, 103:2956-2964.

5. Mountford JC: Human embryonic stem cells: origins, characteristics and potential for regenerative therapy. Transfus Med 2008, 18:1-12.

6. Lessard J, Crabtree GR: Chromatin regulatory mechanisms in pluripotency. Annu Rev Cell Dev Biol 2010, 26:503.

7. Adewumi $\mathrm{O}$, Aflatoonian B, Ahrlund-Richter L, Amit M, Andrews PW, Beighton G, Bello PA, Benvenisty N, Berry LS, Bevan S, Blum B, Brooking J, Chen KG, Choo AB, Churchill GA, Corbel M, Damjanov I, Draper JS, Dvorak P, Emanuelsson K, Fleck RA, Ford A, Gertow K, Gertsenstein M, Gokhale PJ, Hamilton RS, Hampl A, Healy LE, Hovatta O, Hyllner J, et al: Characterization of human embryonic stem cell lines by the International Stem Cell Initiative. Nat Biotechnol 2007, 25:803-816.

8. Giadrossi S, Dvorkina M, Fisher AG: Chromatin organization and differentiation in embryonic stem cell models. Curr Opin Genet Dev 2007, 17:132-138

9. Boyer LA, Lee TI, Cole MF, Johnstone SE, Levine SS, Zucker JP, Guenther MG, Kumar RM, Murray HL, Jenner RG, Gifford DK, Melton DA, Jaenisch R, Young RA: Core transcriptional regulatory circuitry in human embryonic stem cells. Cell 2005, 122:947-956.

10. Noaksson K, Zoric N, Zeng X, Rao MS, Hyllner J, Semb H, Kubista M, Sartipy P: Monitoring differentiation of human embryonic stem cells using real-time PCR. Stem Cells 2005, 23:1460-1467.

11. Draper JS, Pigott C, Thomson JA, Andrews PW: Surface antigens of human embryonic stem cells: changes upon differentiation in culture. $J$ Anat 2002, 200:249-258.

12. Zhang Z: Chapter 6-Neural differentiation. In Human cell culture: volume VI: Embryonic stem cells. The Netherlands: Springer; 2007.

13. Tonge PD, Andrews PW: Retinoic acid directs neuronal differentiation of human pluripotent stem cell lines in a non-cell-autonomous manner. Differentiation 2010, 80:20-30

14. Vandesompele J, De Preter K, Pattyn F, Poppe B, Van Roy N, De Paepe A Speleman F: Accurate normalization of real-time quantitative RT-PCR data by geometric averaging of multiple internal control genes. Genome Biol 2002, 3:research0034.1.

15. Willems E, Leyns L, Vandesompele J: Standardization of real-time PCR gene expression data from independent biological replicates. Anal Biochem 2008, 379:127-129.

16. Marullo M, Zuccato C, Mariotti C, Lahiri N, Tabrizi SJ, Di Donato S, Cattaneo E: Expressed Alu repeats as a novel, reliable tool for normalization of real-time quantitative RT-qPCR data. Genome Biol 2010, 11:R9.

17. Huggett J, Dheda K, Bustin S, Zumla A: Real-time RT-PCR normalisation; strategies and considerations. Genes Immun 2005, 6:279-284.

18. Solanas M, Moral R, Escrich E: Unsuitability of using ribosomal RNA as loading control for northern blot analyses related to the imbalance between messenger and ribosomal RNA content in rat mammary tumors. Anal Biochem 2001, 288:99-102.

19. Willems E, Mateizel I, Kemp C, Cauffman G, Sermon K, Leyns L: Selection of reference genes in mouse embryos and in differentiating human and mouse ES cells. Int J Dev Biol 2006, 50:627-635.

20. Synnergren J, Giesler TL, Adak S, Tandon R, Noaksson K, Lindahl A, Nilsson P, Nelson D, Olsson B, Englund MC, Abbot S, Sartipy P: Differentiating human embryonic stem cells express a unique housekeeping gene signature. Stem Cells 2007, 25:473-480.

21. Hellemans J, Mortier G, De Paepe A, Speleman F, Vandesompele J: qBase relative quantification framework and software for management and automated analysis of real-time quantitative PCR data. Genome Biol 2007, 8:R19.

22. Batzer MA, Deininger PL: Alu repeats and human genomic diversity. Nat Rev Genet 2002, 3:370-379.

23. Rowold DJ, Herrera RJ: Alu elements and the human genome. Genetica 2000, 108:57-72.

24. Shaikh TH, Roy AM, Kim J, Batzer MA, Deininger PL: CDNAs derived from primary and small cytoplasmic Alu (scAlu) transcripts. J Mol Biol 1997, 271:222-234.

25. Trounson A: The production and directed differentiation of human embryonic stem cells. Endocr Rev 2006, 27:208-219.
26. Lupberger J, Kreuzer KA, Baskaynak G, Peters UR, Le Coutre P, Schmidt CA: Quantitative analysis of beta-actin, beta-2-microglobulin and porphobilinogen deaminase mRNA and their comparison as control transcripts for RT-PCR. Mol Cell Probes 2002, 16:25-30.

27. Piehler AP, Grimholt RM, Ovstebø R, Berg JP: Gene expression results in lipopolysaccharide-stimulated monocytes depend significantly on the choice of reference genes. BMC immunology 2010, 11:21.

28. Valceckiene V, Kontenyte R, Jakubauskas A, Griskevicius L: Selection of reference genes for quantitative polymerase chain reaction studies in purified B cells from B cell chronic lymphocytic leukaemia patients. Br $\lrcorner$ Haematol 2010, 151:232-238.

29. Quiroz FG, Posada OM, Gallego-Perez D, Higuita-Castro N, Sarassa C, Hansford DJ, Agudelo-Florez P, Lopez LE: Housekeeping gene stability influences the quantification of osteogenic markers during stem cell differentiation to the osteogenic lineage. Cytotechnology 2010, 62:109-120.

30. Jesnowski R, Backhaus C, Ringel J, Lohr M: Ribosomal highly basic 23-kDa protein as a reliable standard for gene expression analysis. Pancreatology 2002, 2:421-424

31. Curtis KM, Gomez LA, Rios C, Garbayo E, Raval AP, Perez-Pinzon MA, Schiller PC EF1alpha and RPL13a represent normalization genes suitable for RT-qPCR analysis of bone marrow derived mesenchymal stem cells. BMC Mol Biol 2010, 11:61.

32. Wang Y, Han Z, Yan S, Mao A, Wang B, Ren H, Chi Y: Evaluation of suitable reference gene for real-time PCR in human umbilical cord mesenchymal stem cells with long-term in vitro expansion. In Vitro Cell Dev Biol Anim 2010, 46:595-599.

33. Kenmochi N, Kawaguchi T, Rozen S, Davis E, Goodman N, Hudson TJ, Tanaka T, Page DC: A map of 75 human ribosomal protein genes. Genome Res 1998, 8:509-523.

34. Vermeulen J, De Preter K, Lefever S, Nuytens J, De Vloed F, Derveaux S, Hellemans J, Speleman F, Vandesompele J: Measurable impact of RNA quality on gene expression results from quantitative PCR. Nucleic Acids Res 2011, 39:e63.

35. O'Leary T, Heindryckx B, Lierman S, Van der Jeught M, Menten B, Deforce D, Cornelissen R, De Sousa Lopes SC, De Sutter P: The influence of early embryo traits on human embryonic stem cell derivation efficiency. Stem Cells Dev 2011, 20:785-793.

36. Lefever S, Vandesompele J, Speleman F, Pattyn F: RTPrimerDB: the portal for real-time PCR primers and probes. Nucleic Acids Res 2009, 37:D942-D945.

doi:10.1186/1471-2199-14-21

Cite this article as: Vossaert et al: Reference loci for RT-qPCR analysis of differentiating human embryonic stem cells. BMC Molecular Biology 2013 14:21.

\section{Submit your next manuscript to BioMed Central and take full advantage of:}

- Convenient online submission

- Thorough peer review

- No space constraints or color figure charges

- Immediate publication on acceptance

- Inclusion in PubMed, CAS, Scopus and Google Scholar

- Research which is freely available for redistribution 